\title{
Bovine leukaemia virus DNA in fresh milk and raw beef for human consumption
}

\author{
N. N. OLAYA-GALÁN ${ }^{1,2 * \dagger}$, A. P. CORREDOR-FIGUEROA ${ }^{2} \dagger$, T. C. GUZMÁN-GARZÓN ${ }^{2}$, \\ K. S. RÍOS-HERNANDEZ ${ }^{2}$, S. P. SALAS-CÁRDENAS ${ }^{2}$, M. A. PATARROYO ${ }^{3,4}$ AND \\ M. F. GUTIERREZ ${ }^{2}$ \\ ${ }^{1}$ PhD Programme in Biomedical and Biological Sciences, Universidad del Rosario, Bogotá, Colombia \\ ${ }^{2}$ Grupo de Enfermedades Infecciosas, Laboratorio de Virología, Departamento de Microbiología, \\ Pontificia Universidad Javeriana, Bogotá, Colombia \\ ${ }^{3}$ Molecular Biology and Immunology Department, Fundación Instituto de Inmunología de Colombia (FIDIC), \\ Bogotá, Colombia \\ ${ }^{4}$ Basic Sciences Department, School of Medicine and Health Sciences, Universidad del Rosario, Bogotá, \\ Colombia
}

Received 27 February 2017; Final revision 16 August 2017; Accepted 6 September 2017; first published online 28 September 2017

\section{SUMMARY}

Bovine leukaemia virus (BLV) is the causative agent of enzootic bovine leucosis, which has been reported worldwide. BLV has been found recently in human tissue and it could have a significant impact on human health. A possible hypothesis regarding viral entry to humans is through the consumption of infected foodstuffs. This study was aimed at detecting the presence of BLV DNA in raw beef and fresh milk for human consumption. Nested PCR directed at the BLV gag gene (272 bp) was used as a diagnostic test. PCR products were confirmed by Sanger sequencing. Forty-nine per cent of the samples proved positive for the presence of proviral DNA. This is the first study highlighting the presence of the BLV gag gene in meat products for human consumption and confirms the presence of the viral DNA in raw milk, as in previous reports. The presence of viral DNA in food products could suggest that viral particles may also be found. Further studies are needed to confirm the presence of infected viral particles, even though the present findings could represent a first approach to BLV transmission to humans through foodstuff consumption.

Key words: Bovine leukaemia virus, foodborne infection, fresh milk, raw meat, zoonosis.

\section{INTRODUCTION}

Bovine leukaemia virus (BLV) belongs to the genus Deltaretrovirus, family Retroviridae, subfamily Oncovirinae. This is an oncogenic virus that was first

\footnotetext{
* Author for correspondence: N. N. Olaya-Galán, Grupo de Enfermedades Infecciosas, Laboratorio de Virología, Departamento de Microbiología, Pontificia Universidad Javeriana, Carrera 7 No. 40 - 62, Building 50 Lab. 123, Bogotá, Colombia. (E-mail: nuryolaya@gmail.com)

$\dagger$ These authors contributed equally to this work.
}

isolated in 1969 and is the aetiological agent of enzootic bovine leucosis (EBL), one of the most frequently occurring neoplastic diseases in cattle [1]; about a third of BLV-infected cows develop persistent lymphocytosis, $1-5 \%$ of them developing the late stage of the disease that is associated with B-cell neoplasm [2]. This retrovirus is closely related to the types of human lymphotropic T-cell leukaemia virus (HTLV-1 and -2) [3]. BLV integrates its genome in target bovine cells, so that all infected animals are persistently infected and become carriers of the virus during the course of 
their lives, thereby having a negative impact on the animals' immune system and, consequently, induces losses in milk production, poorer yield regarding weight and induced abortions in the animals $[1,4,5]$.

A few studies have revealed the presence of DNA and proteins of BLV in human breast tissue samples, proposing that these findings could be considered as a hazardous factor for breast cancer development [6-9]; albeit some different investigations have not found evidence of the virus in people [10, 11], there is proof that a bovine virus is found in human beings, perhaps related to a zoonosis infection. However, it is still not known how BLV is transmitted to humans. Transmission in cattle could be mediated by horizontal or vertical transmission. Vertical transmission includes perinatal transmission through blood or transplacental passage and post-natal infection routes through colostrum and milk consumption [12, 13]. Horizontal transmission could occur by direct contact between infected and non-infected animals, as well as veterinary practices due to using contaminated instruments on many animals without sterilising them between procedures and animals, including tattooing cattle, vaccination and rectal palpations [14]. Conversely, it has been suggested that humans might become infected by consuming foodstuffs from infected animals, through the direct contact involved in livestock practices or vaccines produced with contaminated cattle sera [7, 15]. Although the transmission route has not yet been established, it could be implicated in as-yet-unknown human health issues such as the emergence of new diseases, taking into account that BLV is described as an oncogenic virus.

Food for human consumption has been proposed as a potential source of pathogen transmission. Several viral infections are related to foodborne diseases; enteric viruses, such as rotaviruses and noroviruses, are amongst the viral agents most frequently transmitted by foodstuffs; these agents are transmitted as free viral particles through faecal contamination of foodstuffs for direct consumption, such as fruit and vegetables and (in some exceptions) meat products $[16,17]$. Some other viral infections require the presence of infected cells to transmit the agent to other hosts; this is the case of hepatitis A virus and hepatitis E virus (HEV) that have been found in meat products, such as sausages, liver and pork [18-21].

There are other diseases that are, in principle, associated with foodstuff consumption but where the causative agent remains unknown [22]; in spite of most of them being associated with gastrointestinal diseases, there could be other types of pathogens in foodstuffs that are still unknown. This could thus be happening with BLV, involving potential risk for human health. Studies focused on food safety for improving the quality of products prepared for human consumption are needed as foodstuffs could transmit unknown pathogens. This study was thus aimed at evaluating the BLV DNA detection in raw meat and fresh milk (i.e. fresh from milking) for human consumption as a first step in estimating the potential of foodstuffs regarding BLV transmission to humans.

\section{METHODS}

\section{Sample collection}

Convenience sampling was used for obtaining both milk and meat samples, 100 samples were obtained. Fifty beef samples weighing around $15 \mathrm{~g}$ each were obtained from butchers in Bogota whilst the 50 samples of milk were obtained from farms specialising in dairy production located in different parts of Colombia. The milk was collected directly from milking (i.e. before being sent for industrial treatment). The samples were transported to the Virology Laboratory at the Javeriana University in Bogotá where meat samples were stored at $-20{ }^{\circ} \mathrm{C}$ until being processed, whilst milk samples were processed immediately.

\section{Sample preparation and nucleic acid extraction}

Roche High Pure PCR Template Preparation Kit was used for extracting total nucleic acids from milk and meat, following the manufacturer's indications; some modifications were made for solid tissue and liquid samples. Regarding meat, an initial 10-20 mg of rump cut (muscle) was lysed with proteinase $\mathrm{K}$ and the tissue lysis buffer supplied in the DNA extraction kit. Extraction from milk samples first involved cell concentration from an initial $5 \mathrm{ml}$ milk volume through sequential centrifugations at $16000 \mathrm{~g}$ for $20 \mathrm{~min}$ for each cycle (four cycles in total); the pellet so obtained was used for DNA extraction, following the manufacturer's instructions. NanoDrop (Thermo) was used for quantifying the extracted DNA to verify its concentration and purity. The DNA was then frozen $\left(-20^{\circ} \mathrm{C}\right)$ and stored until further use.

\section{PCR amplification: multiplex and nested PCR}

The bovine GAPDH constitutive gene was used as PCR internal control, which was amplified in a 
multiplex PCR together with the virus' gag gene encoding its capsid proteins. PCR tests were done using Roche PCR master mix with specific primers $(0.8 \mathrm{pmol} / \mu \mathrm{l})$ for the aforementioned genes. Both bovine GAPDH and gag primers were previously reported by Buehring et al. [6]. An $857 \mathrm{bp}$ fragment was amplified for the bovine GAPDH gene and a $385 \mathrm{bp}$ fragment for gag. Multiplex PCR conditions included an initial denaturing step at $94{ }^{\circ} \mathrm{C}$ for 5 min, followed by 35 cycles of denaturing at $94^{\circ} \mathrm{C}$ for $30 \mathrm{~s}$, an annealing step at $59 \cdot 3{ }^{\circ} \mathrm{C}$ for $60 \mathrm{~s}$ and a $90 \mathrm{~s}$ extension at $72^{\circ} \mathrm{C}$. A final extension step was performed at $72{ }^{\circ} \mathrm{C}$ for $10 \mathrm{~min}$.

PCR sensitivity was increased by nested PCR for samples where the viral gene was not amplified in multiplex PCR. The first PCR's products were used as templates for the nested PCR. The amplification target was an internal gag fragment (nt 1097-1369), resulting in a 272 bp fragment (also reported by Buehring et al.) [6]. Reaction conditions were the same as those described for multiplex PCR. Annealing temperature was $56{ }^{\circ} \mathrm{C}$ with $30 \mathrm{~s}$ extension time.

The results for both multiplex and nested PCR were visualised on $1.5 \%$ agarose gels prepared in $1 \times \mathrm{TAE}$ (Biorad) dyed with $1 \times$ HydraGreen fluorescent intercalating dye (ACTGene). DNA extracted from a blood sample of an infected animal was used as positive control for BLV and RNase- and DNase-free water as negative amplification control.

\section{Sequencing}

Virus-positive PCR products were purified with PCR product purification kit (Roche High Pure), following the manufacturer's instructions, and then sent to Macrogen Inc. (Seoul, Korea), for Sanger sequencing. The primers (both sense and anti-sense) used for sequencing were the same as those for the nested PCR. BioEdit Sequence Alignment Editor (version 7.2.5) was used for editing and analysing the sequences. Consensus sequences were obtained for each positive sample; the online BLASTn tool was used for verifying the identity of the sequences so obtained.

\section{RESULTS AND DISCUSSION}

BLV has been known and studied as an infectious agent in cattle; however, there are reports of this virus in humans $[6,7,9]$ even though the mechanism by which the virus has reached such host has still not been clarified. Buehring et al. [15, 23] highlighted three main hypotheses for the viral entry to humans. The first considers direct contact with infected animals; however, such hypothesis would necessarily involve viral presence in limited populations (i.e. veterinarians, livestock handlers and/or farmers). Nevertheless, available evidence has revealed that the virus has been found in people who do not necessarily come into direct contact with animals $[6,7,9]$. The second hypothesis concerns possible BLV transmission through vaccine production processes involving the use of BLV-contaminated foetal bovine sera, even though no experimental evidence has been published regarding this issue. The third hypothesis proposes that the virus might infect humans through the consumption of bovine-derived products from BLV-infected cattle [10, 23], leading to the idea of evaluating meat and milk products for human consumption as a possible pathway for viral entry.

Nucleic acids were obtained from fresh milk and raw beef samples (muscle tissues) in the present study in the search for BLV proviral DNA. Internal control (bovine GAPDH) was observed in the multiplex PCR (Fig. 1a). A proviral gag segment was found in 24 out of the 50 milk samples and in 25 of the meat samples. These results represent $49 \%$ of all samples analysed. Most of them were detected by nested PCR, suggesting that the viral load in the samples was considerably low. Figure one shows a representative agarose gel of the results obtained by multiplex PCR (a) where an $857 \mathrm{bp}$ fragment from bovine GAPDH was observed, as well as the external gag fragment in positive control (385 bp); nested PCR (b) from the products obtained in the first PCR with a $272 \mathrm{bp}$ fragment was observed in positive control and the samples analysed here (Figs. $1 a$ and $b$ ).

After sequencing PCR products, gag gene identity was verified using BLAST (NCBI) with previously reported BLV sequences. The results gave $97-99 \%$ identity compared to reference sequences. Such results confirmed that the amplified products obtained from meat and milk samples came from the BLV gag segment.

BLV prevalence in Colombia has been recorded as $67 \cdot 7 \%$ on livestock farms throughout the country and in $43 \%$ of the bovine population, thereby affecting (health-wise and economically) livestock breeding for milk production and meat for human consumption [24]. Understanding the evolution of the disease in cattle (most infected animals going unnoticed due to low symptomatology) [25] and considering its high prevalence in Colombia highlights the fact that infected 


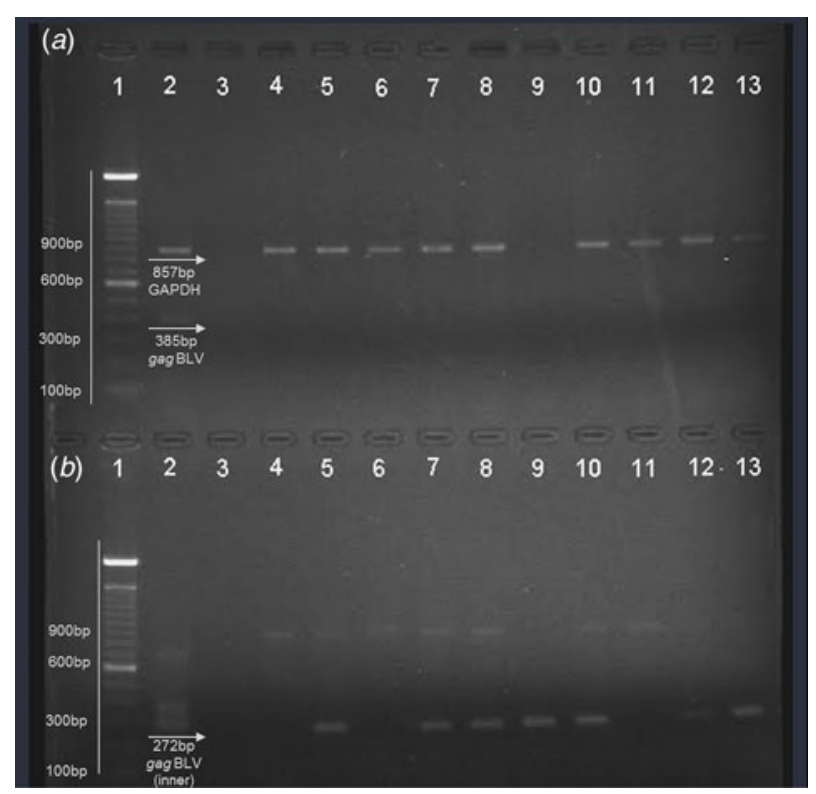

Fig. 1. Representative agarose gel (1.5\%) of field samples. (a) Multiplex PCR. (b) Nested PCR. Lane $1-100$ bp ladder (Invitrogen); lane 2 - positive control; lane 3 - negative control; lane 4-8: beef samples; lane 9-13: milk samples.

animals that have never been detected could be sold for commercialisation, and thus cattle-derived infected products could be distributed in different industries without any government control regarding the presence of the virus. This would favour the disease's dissemination in spite of the fact that EBL was recently established and was considered a disease requiring mandatory notification by the Colombian Agricultural and Livestock Institute [26].

Detection of BLV DNA in cattle-derived foodstuffs (as shown by this study's findings) could serve as a marker, which could suggest a zoonosis (i.e. indicating viral particle transmission by these products). It is worth stressing that cases of zoonosis are considered one of the most important problems regarding infectious disease epidemiology and public health worldwide [27]. Taking the WHO's definition of zoonosis, 'Any disease or infection that is naturally transmissible from vertebrate animals to humans, including all types of pathogenic agents', [28] as well as viral transmission mechanisms, action directed towards avoiding viral dissemination in cattle might prevent the introduction of the pathogen into the human population, even though BLV has not yet been conclusively proven to be a cause of human disease [6, 11, 29].

Foodborne diseases are related with ingesting contaminated foodstuffs with microorganisms, which sometimes could come from an animal origin [30].
Two vehicles have been proposed for viral transmission through foodstuff consumption. Free viral particles in foodstuffs has been related to an exogenous contamination source (i.e. faecal contamination), involving direct consumption of fresh products, such as fruit and vegetables [16]. The other possibility concerns the transmission of viruses through animal-derived products infected with the virus. In this case, animal cells would become carriers of pathogenous agents, introducing them into human beings through consumption of meat from infected animals, trespassing even free viral particles, infected cells or proviral DNA [31]. Reports regarding HEV entry to humans have increased due to products from pigs infected by the virus being consumed, i.e. sausages, liver and poorly cooked pork [18, 19, 21, 32]. This situation has led to acute hepatitis outbreaks where a hitherto disregarded zoonosis has been clearly defined. This study's findings have suggested that a similar situation could be occurring with BLV, giving rise to possible explanations for diseases whose causes have previously been undefined.

The pertinent literature has reported viral particles and viral DNA in cows' milk or colostrum that could be considered a risk factor for transmission to calves [33-36]. Viral DNA was also detected in fresh milk in the present study, thereby agreeing with previous reports, despite not having been described as a risk factor for humans. Bearing this in mind, some other retroviruses could be transmitted by their respective hosts consuming milk, i.e. HTLV, MMTV (mammary murine tumor virus) and also HIV in particular situations [37-39].

Consuming raw milk could be a viable transmission pathway, mostly in developing countries having high raw milk consumption in rural populations. Previous studies have established that industrialisation of milk and pasteurisation processes leads to inactivating viral particles [40-42]; avoiding raw milk consumption would thus be an essential prevention strategy, even if it remains unknown whether BLV can also reach humans by this means.

It is worth highlighting that even though the study's objective was not to determine the presence of complete and infectious viral particles in the samples analysed, the gene fragments found here suggested the virus could be found, since comparing the sequences obtained here with previously reported ones gave $97-99 \%$ identity (i.e. dealing with BLV). Further studies should be aimed at establishing whether consuming the aforementioned foodstuffs transmits infective viral particles, which can then complete their biological cycle in humans. It could be of great interest to 
evaluate viral presence after cooking meat as this could inactivate viral particles and to ascertain whether other mechanisms could be participating in viral transmission [40].

Moreover, this is the first experimental approach reporting the BLV gag gene segment being detected in beef products for human consumption. Questions concerning viral transmission through consuming infected meat have been raised since the reports by Buehring et al. [15]. However, only empirical approaches and inferences about this transmission pathway have been proposed, regarding slaughterhouse practices involving carcinogenic cattle tissue where not only these tissues are distributed to humans, but have been disposed of for dog and cat food products [43]. The data reported here are important for foodborne infections and public health. Prevention policy, which proposes the early detection of pathogenous agents with a possibility to reach humans, depends on the risks for the target population, by controlling the main sources of dissemination [44].

The presence of the BLV DNA in bovine-derived products could be interpreted as a step forward in identifying previously unknown foodborne diseases. Our results suggested that BLV could be considered a potential zoonotic agent, even though non-infectious particles were reported in this study. Evidence of an oncogenic virus' DNA in milk and meat products highlights such foodstuffs as being a potential source of viral transmission to humans and could be the outcome of currently unknown diseases. Such viruses' alternative transmission routes should be studied (i.e. human-to-human transmission). Prevention and control strategies should be enforced to decrease viral prevalence and transmission in cattle and ensure that infected foodstuffs do not become distributed to markets; such alternatives aimed at eradicating the disease have been achieved in some European countries, New Zealand and Australia [5, 45].

\section{ACKNOWLEDGEMENTS}

The authors would like to thank Jason Garry for translating this manuscript and the Vecol Institute for helping with sampling. This research was performed as part of a current project financed by Colciencias, Colombia, as part of call $657 / 2014$ for projects.

\section{DECLARATION OF INTEREST}

None.

\section{REFERENCES}

1. Barez P-Y, et al. Recent advances in BLV research. Viruses 2015; 7: 6080-6088. doi:10.3390/v7112929.

2. Hemmatzadeh $\mathbf{F}$, et al. Interaction between bovine leukemia virus (BLV) infection and age on telomerase misregulation. Veterinary Research Communications 2015; 39: 97-103.

3. Yuan Y, et al. Detection of the BLV provirus from nasal secretion and saliva samples using BLV-CoCoMoqPCR-2: comparison with blood samples from the same cattle. Virus Research 2015; 210: 248-254.

4. Úsuga-Monroy $\mathbf{C}$, Echeverri J, López-Herrera $\mathbf{H}$. Diagnóstico molecular del virus de leucosis bovina en una población de vacas Holstein, Colombia. Archivos de Zootecnia 2015; 64: 383-388.

5. Acaite $\mathbf{J}$, et al. The eradication experience of enzootic bovine leukosis from Lithuania. Preventive Veterinary Medicine 2007; 82: 83-89.

6. Buehring GC, et al. Bovine leukemia virus DNA in human breast tissue. Emerging Infectious Diseases 2014; 20: 772-782.

7. Buehring GC, et al. Exposure to bovine leukemia virus is associated with breast cancer: a case-control study. PLoS ONE 2015; 10: e0134304.

8. Ochoa Cruz A, Uribe A, Gutiérrez M. Estudio del potencial zoonótico del Virus de la Leucosis Bovina y su presencia en casos de cáncer de seno. Universitas Scientiarum. Bogota, Colombia: Pontificia Universidad Javeriana, 2006, pp. 31-40.

9. Mesa G, et al. Bovine leukemia virus gene segment detected in human breast tissue. Open Journal of Medical Microbiology 2013; 3: 84-90.

10. Zhang R, et al. Lack of association between bovine leukemia virus and breast cancer in Chinese patients. Breast Cancer Research 2016; 18: 101.

11. Gillet NA, Willems $\mathbf{L}$. Whole genome sequencing of 51 breast cancers reveals that tumors are devoid of bovine leukemia virus DNA. Retrovirology 2016; 13: 75.

12. Lassauzet ML, et al. Factors associated with in utero or periparturient transmission of bovine leukemia virus in calves on a California dairy. Canadian Journal of Veterinary Research 1991; 55: 264-268.

13. Mekata H, et al. Horizontal transmission and phylogenetic analysis of bovine leukemia virus in two districts of Miyazaki, Japan. The Journal of Veterinary Medical Science 2015; 77: 1115-1120.

14. Kobayashi S, et al. Analysis of risk factors associated with bovine leukemia virus seropositivity within dairy and beef breeding farms in Japan: a nationwide survey. Research in Veterinary Science 2014; 96: 47-53.

15. Buehring GC, Philpott SM, Choi KY. Humans have antibodies reactive with bovine leukemia virus. AIDS Research and Human Retroviruses 2003; 19: 1105-1113.

16. Aw TG, Wengert S, Rose JB. Metagenomic analysis of viruses associated with field-grown and retail lettuce identifies human and animal viruses. International Journal of Food Microbiology 2016; 223: 50-56.

17. Rodríguez-Lázaro D, et al. Presence of pathogenic enteric viruses in illegally imported meat and meat 
products to EU by international air travelers. International Journal of Food Microbiology 2015; 209: 39-43.

18. Rivero-Juarez A, et al. Familial hepatitis E outbreak linked to wild boar meat consumption. Zoonoses and Public Health 2017; 64: 1-5.

19. Di Bartolo I, et al. Detection of hepatitis E virus in pork liver sausages. International Journal of Food Microbiology 2015; 193: 29-33.

20. Fusco G, et al. Prevalence of foodborne viruses in mussels in Southern Italy. Food and Environmental Virology 2017; 9: 187-194.

21. Szabo K, et al. Detection of hepatitis E virus RNA in raw sausages and liver sausages from retail in Germany using an optimized method. International Journal of Food Microbiology 2015; 215: 149-156.

22. Scallan E, et al. Foodborne illness acquired in the United States - unspecified agents. Emerging Infectious Diseases 2011; 17: 16-22.

23. Buehring GC. Response to 'Lack of association between bovine leukemia virus and breast cancer in Chinese patients'. Breast Cancer Research 2017; 19. doi:10.1186/s13058-017-0808-7.

24. Ortega DO, et al. Seroprevalence and risk factors associated with bovine leukemia virus in Colombia. Journal of Veterinary Medicine and Animal Health 2016; 8: 35-43.

25. Aida Y, et al. Mechanisms of pathogenesis induced by bovine leukemia virus as a model for human T-cell leukemia virus. Frontiers in Microbiology 2013; 4: 1-11.

26. Instituto Colombiano Agropecuario. Resolucion 3714'Por la cual se establecen las enfermedades de declaración obligatoria en Colombia'. Bogotá, Colombia: Ministerio de Agricultura, 2015.

27. Hugh-Jones ME, Hubbert WT, Hacstad HV. Section I: Introduction to the zoonoses. ZOONOSES: Recognition, Control, and Prevention. Iowa: Iowa State Press, 1995, pp. 7-37.

28. World Health organization - WHO. Zoonoses and the Human-Animal-Ecosystems Interface. WHO, 2013 (http://www.who.int/zoonoses/en/). Accessed 12 January 2017.

29. Sinha G. Bovine leukemia virus possibly linked to breast cancer. Journal of the National Cancer Institute 2016; 108: djw020.

30. Greig JD, Ravel A. Analysis of foodborne outbreak data reported internationally for source attribution. International Journal of Food Microbiology 2009; 130: 77-87.
31. Hugh-Jones ME, Hubbert WT, Hagstad HV. Principles of Zoonoses Control and Prevention. Zoonoses. Iowa, USA: Iowa State Press, 2000, pp. 79-120.

32. Hartl J, Wehmeyer MH, Pischke S. Acute hepatitis E: two sides of the same coin. Viruses 2016; 8: 299. doi:10.3390/v8110299.

33. Yamada T, et al. Cell infectivity in relation to bovine leukemia virus gp51 and p24 in bovine milk exosomes. PLoS ONE 2013; 8: e77359.

34. Meas S, et al. Vertical transmission of bovine leukemia virus and bovine immunodeficiency virus in dairy cattle herds. Veterinary Microbiology 2002; 84: 275-282.

35. Kobayashi S, et al. Risk factors associated with withinherd transmission of bovine leukemia virus on dairy farms in Japan. BMC Veterinary Research 2010; 6: 1.

36. Gutiérrez G, et al. Characterization of colostrum from dams of BLV endemic dairy herds. Veterinary Microbiology 2015; 177: 366-369.

37. Southern SO, et al. Persistent HTLV-I infection of breast luminal epithelial cells: a role in HTLV transmission? Virology 1998; 241: 200-214.

38. Prameela KK. HIV transmission through breastmilk: the science behind the understanding of current trends and future research. The Medical Journal of Malaysia 2012; 67: 644-651.

39. Lawson JS, et al. Breastfeeding, breast milk and viruses. BMC Women's Health 2007; 7: 17.

40. Baumgartener L, Olson C, Onuma M. Effect of pasteurization and heat treatment on bovine leukemia virus. Journal of the American Veterinary Medical Association 1976; 169: 1189-1191.

41. Chung YS, et al. The effect of pasteurisation on bovine leucosis virus-infected milk bovine leucosis virus. Australian Veterinary Journal 1986; 63: 379-380.

42. Rubino MJ, Donham KJ. Inactivation of bovine leukemia virus-infected lymphocytes in milk. American Journal of Veterinary Research 1984; 45: 1553-1556.

43. emilyproject.org. Emily Project. Emily Project Objective. 2014 (http://www.theemilyproject.org/objective.htm). Accessed 26 January 2017.

44. Kelly TR, et al. One health proof of concept: bringing a transdisciplinary approach to surveillance for zoonotic viruses at the human-wild animal interface. Preventive Veterinary Medicine 2017; 137: 112-118. doi:10.1016/j.prevetmed.2016.11.023.

45. Nuotio L, et al. Eradication of enzootic bovine leukosis from Finland. Preventive Veterinary Medicine 2003; 59: 43-49. 